$\xi=\mathrm{s}$

\title{
Adsorptive removal of catechol and resorcinol by orange flavedo (citrus sinensis): mechanisms based on the flavedo components d-limonene, carotenoids, ascorbates, flavonoids and hydroxycinnamic acids
}

\author{
Kamgaing Théophile ${ }^{1 *}$, Doungmo Giscard ${ }^{1}$, Ngouoko Kouanang Jimmy Julio ${ }^{1}$, \\ Tchieno Melataguia Francis Merlin ${ }^{1}$, Ketcha Joseph Mbadcam ${ }^{2}$ \\ ${ }^{1}$ Laboratory of Noxious Chemistry and Environmental Engineering, University of Dschang P.O. BOX: 67 Dschang, Cameroon \\ ${ }^{2}$ Department of Inorganic Chemistry, Faculty of Science, University of Yaoundé I, P.O. Box 812, Yaoundé-Cameroon \\ *Corresponding author E-mail: theophile.kamgaing@univ-dschang.org
}

\begin{abstract}
Orange flavedo and its adsorption behavior towards catechol (Ctc) and resorcinol (Res) were studied. Adsorption experiments were conducted in batch mode at room temperature. X-ray diffraction (XRD), Scanning electron microscopy (SEM), Energy-dispersive X-ray spectroscopy (EDX), Brunauer-Emmett-Teller (BET) and Fourier transform infrared (FTIR) data were used to characterize the biosorbent. The Effects of various parameters including equilibrium $\mathrm{pH}$, sorbent dosage, initial adsorbate concentration and contact time were investigated. The optimum contact time and $\mathrm{pH}$ for the removal of $\mathrm{Ctc}$ and Res were $35 \mathrm{~min}$ and $\mathrm{pH} 2$ respectively. The adsorption isotherms fitted well with Freundlich model, the adsorption of Ctc and Res being multilayer and the surface of orange flavedo heterogeneous; the pseudo-second order kinetic model better reflects the adsorption phenomena. An adsorption mechanism based on the molecules grafted to the surface of the orange flavedo is proposed in this study. 0.2 gram of the biosorbent was sufficient to completely eliminate 2.2 milligrams of resorcinol and catechol from solution. Therefore, non-modified orange flavedo is a promising candidate, as a lowcost biosorbent, for the removal of Ctc and Res from aqueous solution.
\end{abstract}

Keywords: Orange Flavedo; Adsorption; Catechol; Resorcinol; Adsorption Mechanisms.

\section{Introduction}

Orange is one of the most consumed fruits in the world. 50 million tons are produced annually, Brazil being leader with over 18 million tons. After extracting the juice, orange peels are discarded. Estimated at 25 million tons per year, the orange peels are a perfect example of lost resource. Yet, they contain more ascorbic acid (vitamin C) and more active compounds (D-limonene, hesperidin, naringin, auraptene ...) than the juice and the pulp [1]. The citrus peel consists of the white albedo which contains the primary vascular system of the fruit, the colored outer flavedo which contains oil glands and pigments, and the epidermal layer which contains stomatal guard cells and is covered by the cuticle [2], a thin " $3 \mu \mathrm{m}$ for citrus fruit" continuous polymer that plays a pivotal role in the growth and storage of citrus fruit $[3,4]$. Stomatal pores and flavedo components (ascorbates, flavonoids, terpenoids, pectines etc) give the orange peels interesting surface properties. The stomatal pores also act as a site for penetration of organisms and chemicals into the fruit. Many of these pores become plugged with wax but many remain functional [3]. In this study we focus on the external part of the orange peels (flavedo) whose cuticle is the main barrier through which exchanges are made between the orange and water, gases and various pollutants including Catechol (Ctc) and resorcinol (Res).
Ctc and Res are found in the effluents of industries such as textile, paper and pulp, steel, petrochemical, petroleum refinery, pharmaceutical, cosmetic, dye etc and in the wastewater of synthetic coal fuel conversion process [5], [6]. The toxicity of Ctc towards microorganisms, animals and human cell lines has been reported [79]. Although Ctc is more toxic than Res [7], [10], both are considered as the primary pollutants in wastewater due to their low biodegradability, high oxygen demand, and high toxicity [5], [9]. In this study, the orange flavedo is applied to the removal of Ctc and Res in solution. Before this, spectroscopic and micrographic analyzes of the biosorbent were made to offer an adsorption mechanism that takes into account the functional chemical groups of the outer orange peels.

\section{Materials and method}

\subsection{Preparation and characterization of the biosorbent}

\subsubsection{Adsorbent from orange peel (flavedo)}

Fresh oranges from Nigeria (improved variety) were purchased from Mokolo market in Yaoundé city, Cameroon, washed with running water to remove the soluble impurities, peeled with a sharp knife, ensuring that the flavedo was not harvested alongside the albedo. Peelings (flavedo), once washed and rinsed with distilled water were dried under the sun, then in an oven at $60{ }^{\circ} \mathrm{C}$ for 
$48 \mathrm{~h}$ before being crushed in a grinding mill and sieved. Orange peels of particle size less than $250 \mu \mathrm{m}$ designated EVACSO were stored in plastic bags for subsequent analyzes. The chemical treatment of EVACSO with sodium hydroxide, nitric acid, methanol and acetone leads to less satisfactory yields. For this reason, the biomaterial was used in its natural state to remove Ctc and Res in solution.

\subsubsection{Characterization of orange flavedo (EVACSO)}

\subsubsection{Determination of pHpzc}

The point of zero charge $\left(\mathrm{pH}_{\mathrm{pzc}}\right)$ is the $\mathrm{pH}$ at which the adsorben is neutral in aqueous suspension. It was determined following the procedure given by Lopez-Ramon [11].

\subsubsection{BET analysis}

The Brunauer-Emmett-Teller (BET) specific surface area of the samples was determined by nitrogen adsorption at $77 \mathrm{~K}$ with a Micromeritics instrument, Gemini Model 2380.

\subsubsection{SEM analysis}

Scanning Electron Microscopy (Phillips XL 30, Netherlands) images were taken to know the surface morphology of EVACSO.

\subsubsection{EDX analysis}

Energy dispersive X-ray spectroscopy (EDX) helped to determine the elementary composition of the orange flavedo.

\subsubsection{XRD analysis}

$\mathrm{X}$-ray powder profiles were collected using a Bruker D5005 X-ray diffractometer equipped with sealed $\mathrm{Cu}-\mathrm{K} \alpha$ radiation source $(\lambda=$ $1.54184 \AA$ )

\subsubsection{FTIR analysis}

Fourier Transform Infrared (FTIR) spectroscopy is a helpful too in identifying the presence of certain functional groups on the surface of a solid. The biosorbent was analyzed using a FTIR Bruker Alpha-P spectrophotometer.

\subsection{Preparation of Ctc and Res}

Stock solutions of Ctc and Res (500 mg.L $\left.\mathrm{L}^{-1}\right)$ were obtained by dissolving known amounts of Ctc and Res in hydrogen peroxidewater mixture $(1 / 5 \mathrm{v} / \mathrm{v})$. Several dilutions were made later in the same conditions.

\subsection{Optimization of Ctc and Res adsorption on EVACSO}

The adsorption experiments were conducted in batch mode by mechanical agitation at room temperature. $50 \mathrm{mg}$ of EVACSO of particle size less than $250 \mu \mathrm{m}$ were introduced into a flask containing $15 \mathrm{~mL}$ of $\mathrm{Ctc}$ or Res at the concentration $150 \mathrm{mg} . \mathrm{L}^{-1}$. The mixture was stirred for $35 \mathrm{~min}$ and after filtration, Ctc and Res were analyzed using a UV/Vis spectrophotometer Jenway 6715 , at the wavelengths $279 \mathrm{~nm}$ and $269 \mathrm{~nm}$ respectively. Similar assays were performed by varying the contact time, $\mathrm{pH}$, adsorbent dosage and the initial concentrations of Ctc and Res. Adsorption percentage $(\% \mathrm{R})$ and amount $\left(\mathrm{Q}_{\mathrm{E}}\right)$ adsorbed were obtained from equations (1) and (2) respectively.

$$
\begin{aligned}
& \% R=\frac{\left(C_{0}-C_{E}\right) 100}{C_{0}} \\
& Q_{E}=\frac{\left(C_{0}-C_{E}\right) V}{m}
\end{aligned}
$$

$\mathrm{C}_{0}\left(\mathrm{mg} . \mathrm{L}^{-1}\right)$ and $\mathrm{C}_{\mathrm{E}}\left(\mathrm{mg} . \mathrm{L}^{-1}\right)$ are respectively the initial concentration and the equilibrium concentration of Ctc and Res, $\mathrm{m}(\mathrm{mg})$ is the mass of the adsorbent and $\mathrm{V}(\mathrm{L})$ is the volume of the solution.

\subsubsection{Effect of contact time}

In ten bottles of $25 \mathrm{~mL}$ each were introduced $0.050 \mathrm{~g}$ of EVACSO and $15 \mathrm{~mL}$ of $150 \mathrm{mg} . \mathrm{L}^{-1}$ sorbate. The mixtures were shaken at a constant speed and filtered at regular time intervals: 5-120 min. The filtrate was then analyzed by UV-Vis spectrophotometry to determine the residual concentration of Ctc and Res. The equilibrium time is obtained graphically by plotting quantity adsorbed at time $\mathrm{t}\left(\mathrm{Q}_{\mathrm{t}}\right)$ against time $(\mathrm{t})$.

\subsubsection{Effect of pH}

The approach is the same as previously but at variable $\mathrm{pH}$ in the range from 2-11 and after a contact time of $35 \mathrm{~min}$. The $\mathrm{pH}$ of the medium is adjusted using nitric acid $0.1 \mathrm{M}$ or sodium hydroxide $0.1 \mathrm{M}$. The optimum $\mathrm{pH}$ is obtained graphically by plotting quantity adsorbed ( $\left.\mathrm{Q}_{\text {ads }}\right)$ against $\mathrm{pH}$.

\subsubsection{Effect of initial concentration}

$50 \mathrm{mg}$ of EVACSO were added to various solutions of Ctc and Res $\left(50-210 \mathrm{mg} \cdot \mathrm{L}^{-1}\right)$, the $\mathrm{pH}$ of the medium adjusted to 2 for an optimal contact time of $35 \mathrm{~min}$.

\subsubsection{Effect of the absorbent dosage}

The optimal dosage of EVACSO at a given concentration of Ctc or Res is obtained by keeping constant the previously optimized parameters and by varying the mass of EVACSO $(0.06-0.18 \mathrm{~g})$.

\subsection{Kinetics adsorption studies}

Kinetic studies were carried out at constant concentration of Ctc and Res (150 mg.L $\left.\mathrm{L}^{-1}\right)$ and constant mass of EVACSO (50 mg). The mixture was stirred vigorously at increasing time interval, and then filtered and the adsorbate residue determined. To fit experimental data, a number of kinetic models were used. These are:

\subsubsection{Pseudo-first order kinetic model}

The Lagergren pseudo-first order model [12] is the earliest known equation describing the adsorption rate based on the adsorption capacity. The differential equation is generally expressed a follows:

$$
\frac{d Q}{d t}=K_{1}\left(Q_{E}-Q_{t}\right)
$$

$\mathrm{Q}_{\mathrm{E}}\left(\mathrm{mg} \cdot \mathrm{g}^{-1}\right)$ and $\mathrm{Q}_{\mathrm{t}}\left(\mathrm{mg} \cdot \mathrm{g}^{-1}\right)$ being the adsorption capacity at equilibrium and at time $t$ respectively and $\mathrm{K}_{1}\left(\mathrm{~min}^{-1}\right)$ the rate constant of pseudo-first order adsorption. After integration, equation (3) becomes equation (4):

$$
\ln \left(\mathrm{Q}_{\mathrm{E}}-\mathrm{Q}_{\mathrm{t}}\right)=\ln Q_{E}-K_{\mathrm{l}} t
$$

\subsubsection{Pseudo-second order kinetic model}

The characteristic equation of this model [13] is given by equation (5):

$$
\frac{d Q_{t}}{d t}=K_{2}\left(Q_{E}-Q_{t}\right)^{2}
$$

Better expressed as:

$$
\frac{t}{Q_{t}}=\frac{1}{K_{2} Q_{E}^{2}}+\frac{t}{Q_{E}}
$$


$\mathrm{K}_{2}$ being the rate constant for the pseudo-second order adsorption (g. mg-1 $\left.\cdot \mathrm{min}^{-1}\right)$.

\subsubsection{The Elovich kinetic model}

The Elovich kinetic equation is expressed as equation (7):

$$
\frac{d Q_{t}}{d t}=\alpha \exp ^{\left(\beta Q_{t}\right)}
$$

Where $\alpha\left(\mathrm{mg} \cdot \mathrm{g}^{-1} \cdot \mathrm{min}^{-1}\right)$ and $\beta\left(\mathrm{g} \cdot \mathrm{min}^{-1}\right)$ are the initial adsorption rate and the desorption constant respectively. Once integrated equation (7) becomes equation (8):

$$
Q_{t}=\frac{1}{\beta} \ln (\alpha \beta)+\frac{1}{\beta} \ln t
$$

\subsubsection{Intraparticle diffusion model}

The intraparticle diffusion has often been regarded as the limiting step of most adsorption processes. The equation that better reflects the phenomenon is the following:

$$
Q_{t}=K_{d} t^{1 / 2}+C
$$

Where $\mathrm{Q}_{\mathrm{t}}\left(\mathrm{mg} \cdot \mathrm{g}^{-1}\right)$ and $\mathrm{K}_{\mathrm{d}}$ are the instantaneous amount of adsorbate per unit gram of adsorbent and the diffusion constant respectively. $\mathrm{C}$ is a constant giving an idea about the thickness of the boundary layer.

\subsection{Batch equilibrium experiments (adsorption experi- ments)}

The adsorption isotherms derived from empirical models help to determine the type of interaction (chemisorption or physisorption) which leads to the adsorption of a molecule on the surface of a solid. Models commonly used are that of Langmuir, Freundlich and Temkin.

\subsubsection{The Langmuir isotherm}

The Langmuir isotherm model ensures a fixation of the adsorbate in a single layer on uniform sites and in a limited number of the adsorbent, without the possibility of transmigration of the adsorbate in the plane of the surface [14]. Equation (10) gives the linear form of the characteristic equation of this model:

$$
\frac{C_{E}}{Q_{E}}=\frac{1}{Q_{m} K_{L}}+\frac{C_{E}}{Q_{m}}
$$

Where $\mathrm{Q}_{\mathrm{E}}\left(\mathrm{mg}^{\mathrm{g}} \mathrm{g}^{-1}\right)$ is the amount of adsorbate (Ctc or Res) adsorbed per unit mass of adsorbent (EVACSO), $\mathrm{C}_{\mathrm{E}}\left(\mathrm{mg} . \mathrm{L}^{-1}\right)$ the equilibrium concentration of the adsorbate, $\mathrm{Qm}_{\mathrm{m}}\left(\mathrm{mg}_{\mathrm{g}} \mathrm{g}^{-1}\right)$ and $\mathrm{K}_{\mathrm{L}}$ $\left(\mathrm{L} . \mathrm{mg}^{-1}\right)$ are the monolayer adsorption capacity and the Langmuir adsorption constant respectively.

\subsubsection{The freundlich isotherm}

The Freundlich isotherm, based on adsorption on a heterogeneous surface [15] is characterized by the following equation

$$
\ln Q_{E}=\ln K_{F}+\frac{1}{n} \ln C_{E}
$$

Where $\mathrm{K}_{\mathrm{F}}$ is a constant related to the adsorption capacity and $\frac{1}{n}$ is an empirical parameter related to the adsorption intensity, which varies with the heterogeneity of the material [16]. If the value of $\frac{1}{n}$ is below one, it indicates a normal adsorption.

\subsubsection{The temkin isotherm}

The following equation is a fundamental characteristic of the Temkin model [17]:

$$
Q_{E}=Q_{m} \frac{R T}{\Delta Q} \ln K_{T} C_{E}
$$

Where $\mathrm{Q}_{\mathrm{E}}$ is the amount adsorbed at equilibrium, $\mathrm{K}_{\mathrm{T}}$ the equilibrium constant and $\Delta \mathrm{Q}$ the heat of adsorption. The linear form of this equation is:

$$
Q_{E}=Q_{m} \frac{R T}{\Delta Q} \ln K_{T}+Q_{m} \frac{R T}{\Delta Q} \ln C_{E}
$$

By plotting $Q_{E}=f\left(\ln C_{E}\right)$, one obtains a straight line whose slope and intercept make it possible to determine the heat of adsorption $\Delta \mathrm{Q}$ and the equilibrium constant $\mathrm{K}_{\mathrm{T}}$.

\section{Results and discussion}

\subsection{Characterization of the adsorbent material (EVACSO)}

\subsubsection{The point of zero charge (pHpzc)}

The $\mathrm{pH}$ of zero charge EVACSO is 4.72 . Thus, when the $\mathrm{pH}$ of the medium is less than 4.72 , the surface charge of the biomaterial is generally positive. Under these conditions, the EVACSO-Ctc and EVACSO-Res interactions are attractive through hydrogen bond formation or covalent bond formation.

When the $\mathrm{pH}$ is higher than 4.72 , the surface charge is negative and interactions become repulsive.

\subsubsection{BET analysis}

Table 1 indicated the BET surface area of some natural biosorbents. It should be noted that the surface area of orange flavedo $\left(0.72 \mathrm{~m}^{2} \cdot \mathrm{g}^{-1}\right)$ is the same as that of the sawdust, but significantly higher than that of the rice husk.

Table 1: Specific Surface Area of Some Natural Sorbents

\begin{tabular}{lll}
\hline Sorbent & BET surface area $\left(\mathrm{m}^{2} . \mathrm{g}^{-1}\right)$ & Reference \\
\hline Peat & 1.02 & {$[18]$} \\
Sawdust & 0.72 & {$[18]$} \\
Bagasse & 1.67 & {$[18]$} \\
Rice husk & 0.24 & {$[18]$} \\
Orange flavedo & 0.72 & This study \\
\hline
\end{tabular}

\subsubsection{SEM analysis}

The morphology of EVACSO was characterized using scanning electron microscopy (SEM). Fig. 1 shows the SEM micrograph of EVACSO, revealing the irregular and porous surface of the sample used. This confirms similar observations by Arami et al. [19] and Mafra et al. [20]. 


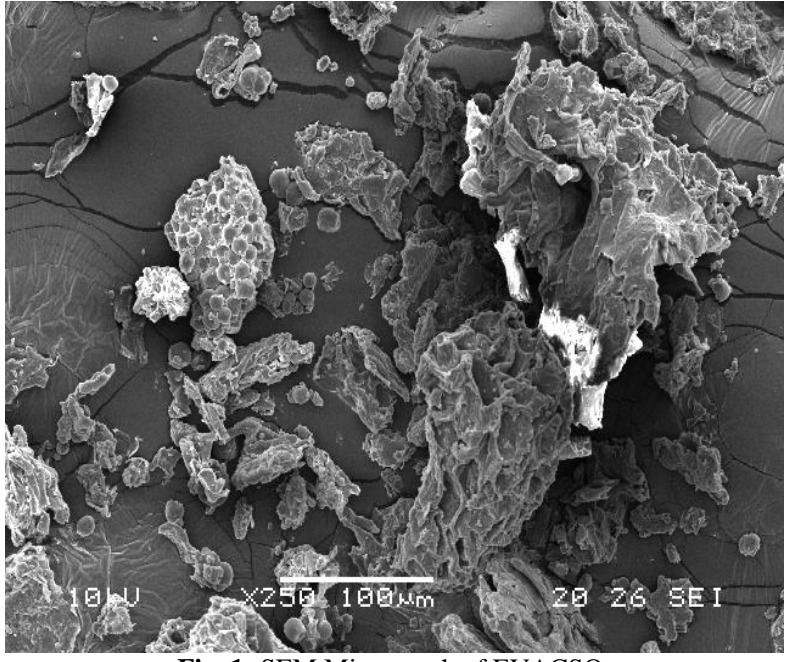

Fig. 1: SEM Micrograph of EVACSO.

\subsubsection{EDX analysis}

The bulk composition of EVACSO was investigated by energy dispersive X-ray (EDX) measurements. The EDX spectrum obtained is shown in Fig. 2. The atomic and weight percentages of the agricultural waste material are summarized in table 2 , with carbon and oxygen being the most abundant elements by weight.

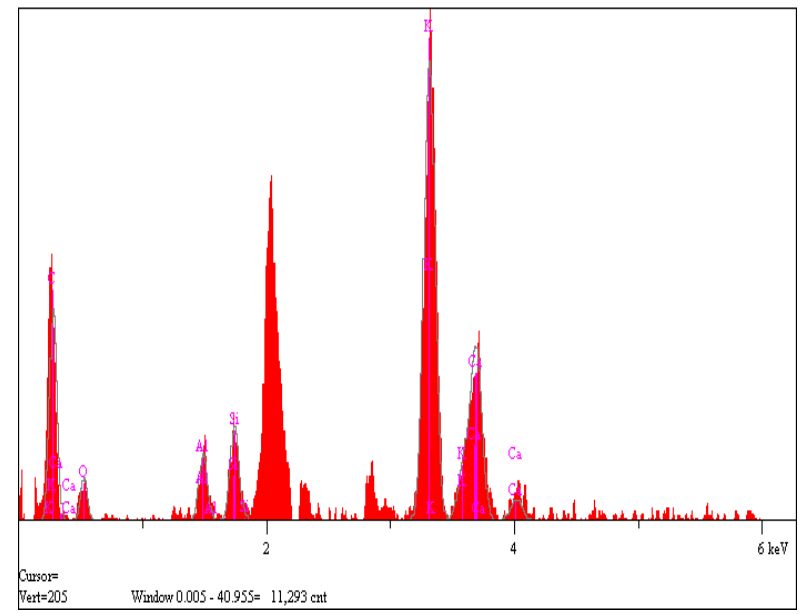

Fig. 2: EDX Spectrum of EVACSO.

\begin{tabular}{lll} 
& Table 2: Elemental Analysis of EVACSO \\
\hline Element & wt\% & At\% \\
\hline $\mathrm{K}$ & 12.867 & 26.834 \\
$\mathrm{O}$ & 20.585 & 17.568 \\
$\mathrm{C}$ & 55.788 & 35.741 \\
$\mathrm{Al}$ & 2.035 & 2.928 \\
$\mathrm{Si}$ & 2.693 & 4.034 \\
$\mathrm{Ca}$ & 6.032 & 12.895 \\
\hline
\end{tabular}

\subsubsection{XRD analysis}

EVACSO was further characterized by powder X-ray diffraction (XRD). The diffractogram obtained is depicted by Fig. 3. The diffused diffraction peaks around $20^{\circ}$ corresponds to the amorphous structures of carbon [21]. The absence of any ordered crystalline structure is confirmed.

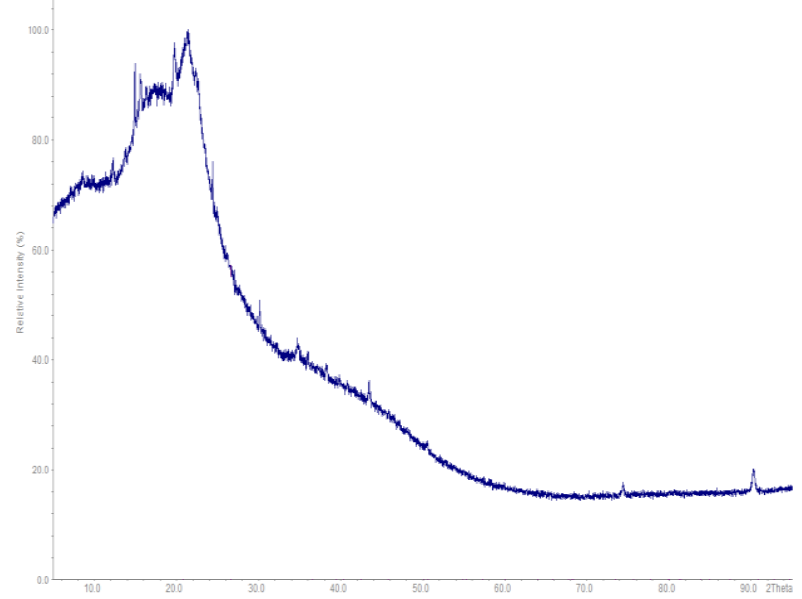

Fig. 3: XRD Spectrum of EVACSO.

\subsubsection{FTIR analysis}

Fourier transform infrared (FTIR) spectroscopy was used to identify the functional groups present in EVACSO. The FTIR spectrum obtained in the $4000-400 \mathrm{~cm}^{-1}$ spectral region is shown in Fig. 4 and the band assignments summarized in table 3 . The broad band at the high energy region centered around $3293.32 \mathrm{~cm}^{-1}$ is assigned to $\mathrm{O}-\mathrm{H}$ stretching vibrations (flavanone aglycones and their respective glycosides, vitamin $\mathrm{C}$, hydroxycinnamic acids). The peak at $2923.33 \mathrm{~cm}^{-1}$ corresponds to the C-H stretching of methyl (limonene...) and methylene moieties (aglycones and glycosides) while the band at $1736.75 \mathrm{~cm}^{-1}$ can be assigned to $\mathrm{C}=\mathrm{O}$ stretching vibrations (flavanone aglycones and glycosides, vitamin $\mathrm{C}$, hydroxycinnamic acids). The adsorption bands around $529 \mathrm{~cm}^{-1}$ can be attributed to $\mathrm{Si}-\mathrm{O}$ bending vibrations.

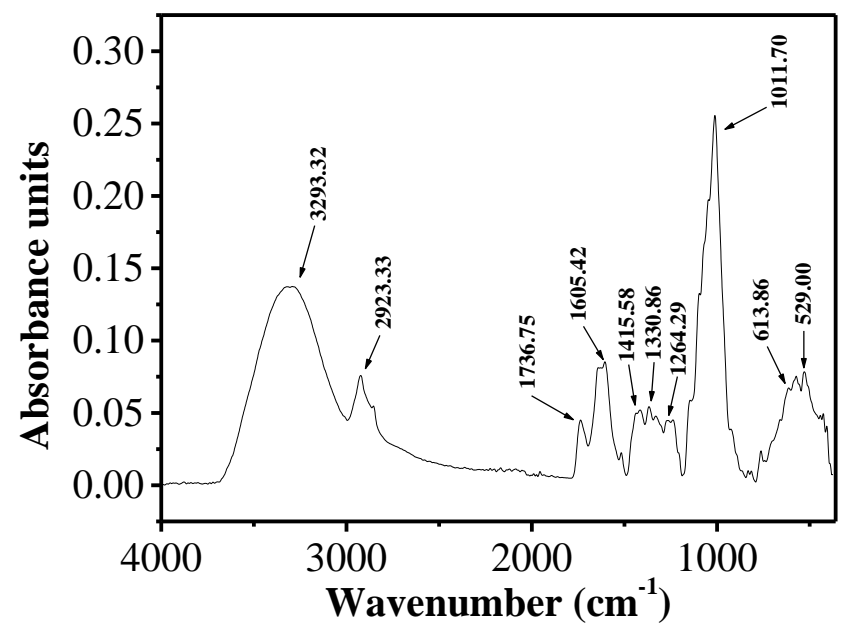

Fig. 4: FTIR Spectrum of EVACSO.

Table 3: Characteristic Infrared Bands of EVACSO

\begin{tabular}{ll}
\hline Wavenumber $\left(\mathrm{cm}^{-1}\right)$ & Assignment \\
\hline 3293.32 & $v \mathrm{O}-\mathrm{H}$ \\
2923.33 & $v \mathrm{C}-\mathrm{H}$ \\
1736.75 & $v \mathrm{C}=\mathrm{O}$ \\
1605.42 & $v \mathrm{C}=\mathrm{C}$ \\
1415.58 & $\delta_{\mathrm{as}} \mathrm{C}-\mathrm{H}$ \\
1367.52 & $\delta_{\mathrm{s}} \mathrm{C}-\mathrm{H}$ \\
1330.86 & $\delta \mathrm{CH}_{2}$ \\
1264.29 & $v \mathrm{Aryl}-\mathrm{OH}$ \\
1011.70 & $v \mathrm{C}-\mathrm{O}$ \\
613.86 & $\delta \mathrm{C}=\mathrm{O}$ \\
529.00 & $\delta \mathrm{Si}-\mathrm{O}$ \\
\hline
\end{tabular}

$v$ : stretching, $\delta$ : bending, $\delta_{\text {as: }}$ : asymmetrical bending, $\delta_{\mathrm{s}}$ : symmetrical bending

\subsection{Adsorption experiments}




\subsubsection{Effect of contact time}

The adsorption of Res and Ctc occurs in two steps (Fig. 5). The first step which is rapid occurs in less than $10 \mathrm{~min}$ and the quantity adsorbed for both was $15 \mathrm{mg} \cdot \mathrm{g}^{-1}$. Indeed, the adsorbent adsorption sites are uncongested at this stage: no obstacles that may hinder the diffusion of molecules Ctc and Res. After $35 \mathrm{~min}$, the second step occurs with a maximum adsorbed quantity of $25 \mathrm{mg} \cdot \mathrm{g}^{-1}$. At this stage, the repulsive forces between the adsorbed molecules and molecules in solution become important. This phenomenon has been described by many authors [22], [23].

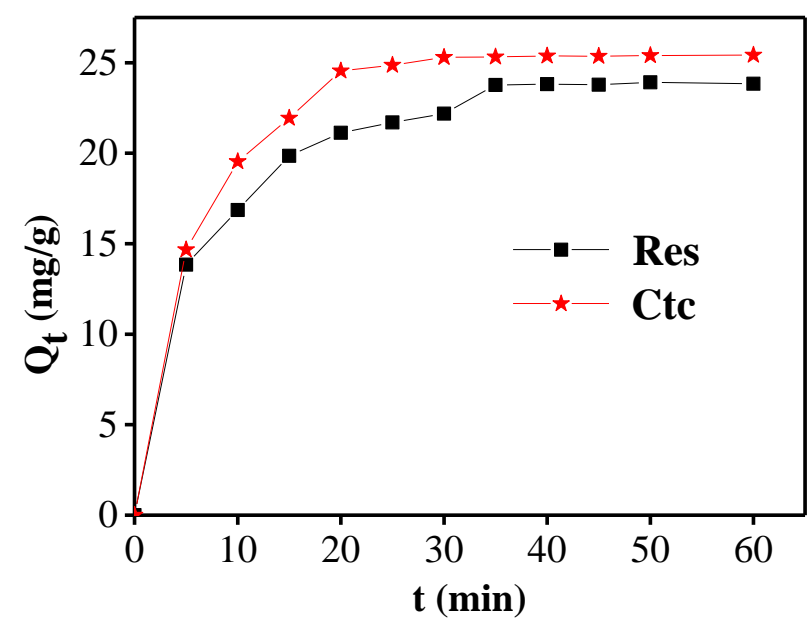

Fig. 5: Effect of the Contact Time on the Adsorption of Res and Ctc by EVACSO. Test Conditions: $15 \mathrm{Ml}$ of $150 \mathrm{Mg} . \mathrm{L}^{-1}$ analyte, $50 \mathrm{Mg}$ of Adsorbent, Stirring Speed 125 Rev/Min, Room Temperature.

\subsubsection{Effect of pH on Ctc and Res adsorption}

The $\mathrm{pH}$ is an important parameter in the adsorption because it acts both on the surface charge of the adsorbent and on the adsorption medium; it significantly influences the interactions (repulsive/attractive) that take place between adsorbate and adsorbent, and between adsorbate molecules [24]. It is at $\mathrm{pH} 2$ (very acidic $\mathrm{pH}$ ) that the adsorption of Ctc and Res is optimal (Fig. 6). Indeed, when the $\mathrm{pH}$ increases, while the adsorbent surface charge becomes negative $(\mathrm{pH}>\mathrm{pH}$ ZPC $)$, Ctc and Res become phenolates (catecholate, resorcinolate). Electrostatic repulsion between adsorbent and adsorbate then become paramount.

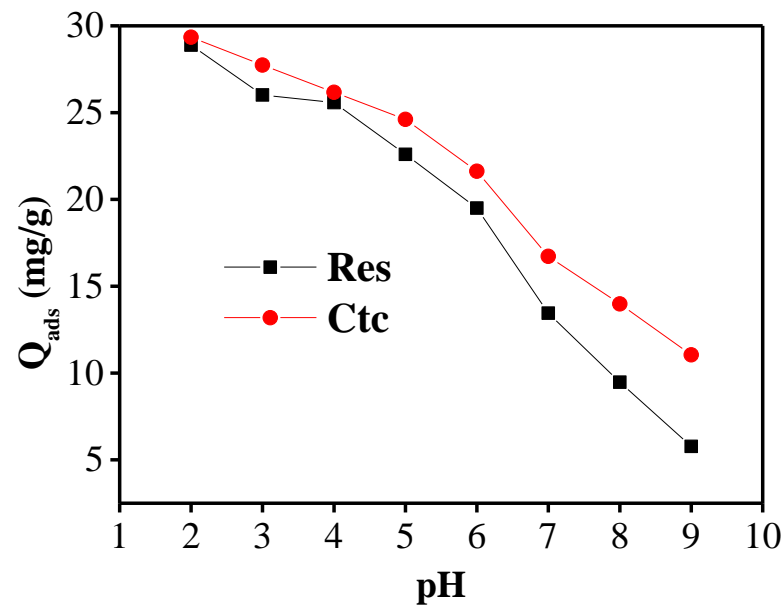

Fig. 6: Effect of $\mathrm{Ph}$ on the Adsorption of Res and Ctc by EVACSO. Experimental Conditions: $15 \mathrm{Ml}$ of $150 \mathrm{Mg} \cdot \mathrm{L}^{-1}$ Analyte, $50 \mathrm{Mg}$ of Adsorbent, Stirring Speed 125 Rev/Min, Contact Time 35 Min, Room Temperature.

\subsubsection{Effect of adsorbent dosage}

At a given concentration of analyte, the adsorption efficiency increases with the adsorbent dosage (Fig. 7). The more the mass of adsorbent increases, the more the binding sites of the adsorbate become important, and the best is adsorption efficiency. However, $100 \mathrm{mg}$ of EVACSO are enough to completely eliminate the Res in solution. It takes more $(160 \mathrm{mg})$ to adsorb catechol at about $93 \%$. Fig. 7 shows that below $60 \mathrm{mg}$ of adsorbent added, Ctc is more adsorbed than Res but above, Res is more adsorbed than Ctc.

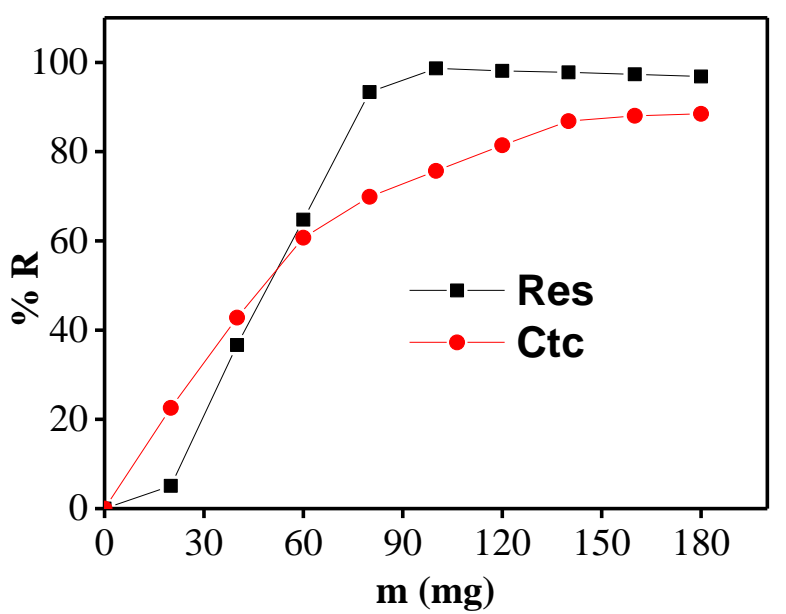

Fig.7: Effect of the Adsorbent Dosage on the Adsorption of Res and Ctc by EVACSO. Experimental Conditions: $15 \mathrm{Ml}$ Of $150 \mathrm{Mg} . \mathrm{L}^{-1}$ Analyte, $\mathrm{Ph}$ 2, Stirring Speed 125 Rev/Min, Contact Time 35 Min, Room Temperature.

\subsubsection{Effect of initial adsorbate concentration}

The adsorption of Ctc and Res on orange flavedo increases with the concentration (Fig. 8). In the range of concentrations studied, the maximum adsorption capacity of the biosorbent is $27.5 \mathrm{mg} . \mathrm{g}^{-1}$ for Ctc and $34.4 \mathrm{mg} \cdot \mathrm{g}^{-1}$ for Res.

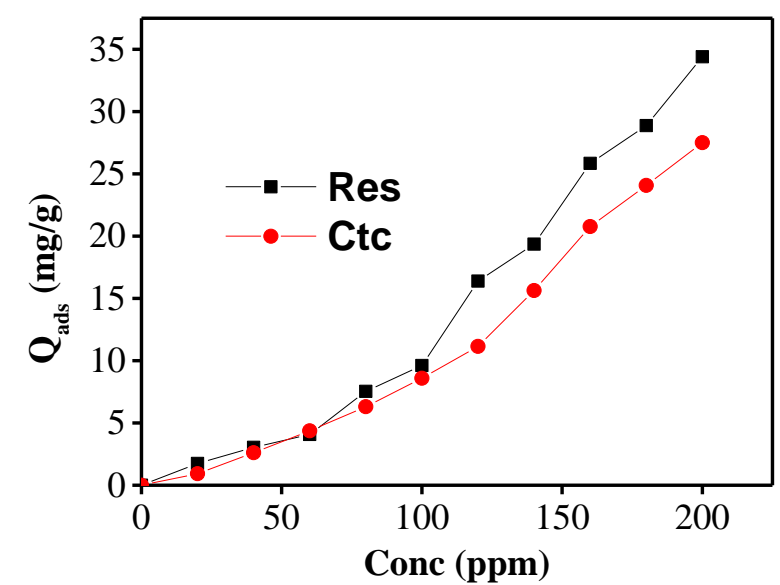

Fig.8: Effect of the Initial Concentration on the Adsorption of Res and Ctc by EVACSO. Experimental Conditions: $15 \mathrm{Ml}$ of Analyte, $50 \mathrm{Mg}$ of Adsorbent, Ph 2, Stirring Speed 125 Rev/Min, Contact Time 35 Min, Room Temperature.

\subsubsection{Adsorption isotherms}

Linear plots of the models of Langmuir, Freundlich and Temkin are represented in Figs. 9-11. The values of correlation coefficients are significant for all models studied $\left(\mathrm{R}^{2}>0.9\right.$, table 4$)$. However, the Freundlich isotherm $\left(\mathrm{R}^{2}=0.993\right)$ and that of Langmuir $\left(\mathrm{R}^{2}=0.977\right)$ better reveal the adsorption phenomena of Res on the surface of the orange flavedo (EVACSO). This is also the case with Ctc (Langmuir, $\mathrm{R}^{2}=0.997$; Freundlich, $\mathrm{R}^{2}=0.9896$ ). However the Freundlich model is to be consider as Langmuir Qm values (16 mg. $\mathrm{g}^{-1}$ for Ctc and $4.47 \mathrm{mg} . \mathrm{g}^{-1}$ for Res) are well below the experimental values $\left(34.4 \mathrm{mg} \cdot \mathrm{g}^{-1}\right.$ for Res and $27.5 \mathrm{mg} \cdot \mathrm{g}^{-1}$ for $\mathrm{Ctc})$. On the other hand, the $\mathrm{n}$ value of Freundlich is less than 1 in both cases, indicating the physisorption of Ctc and Res. Since the experimental data better obey the Freundlich isotherm and adsorption being physisorption type, it is probable that the adsorption of 
Ctc and Res is multilayer and the surface of flavedo heterogeneous. Other authors have argued in the same vein with orange peels applied to chrome removal [25].

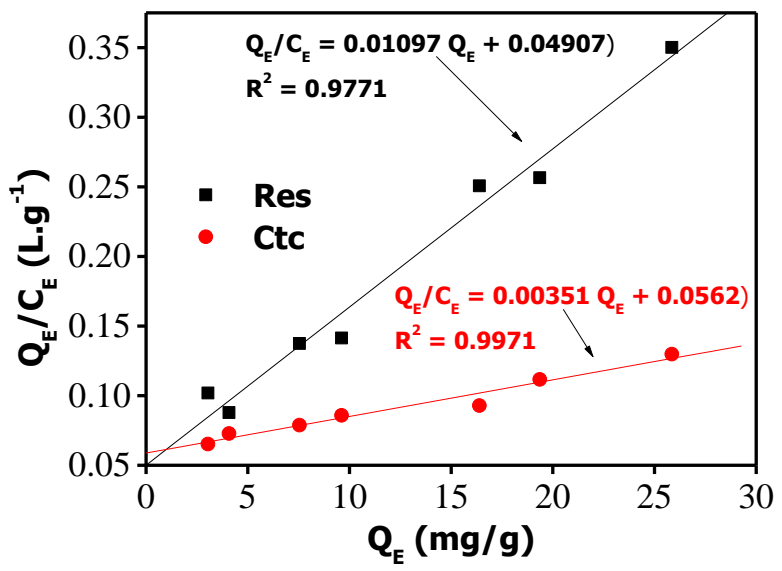

Fig. 9: Langmuir Isotherm Sorption Model. Experimental Conditions: 15 Ml of (60-180 Mg.L $\left.{ }^{-1}\right)$ Analyte, $50 \mathrm{Mg}$ of Adsorbent, Ph 2, Stirring Speed 125 Rev/Min, Contact Time 35 Min, Room Temperature.

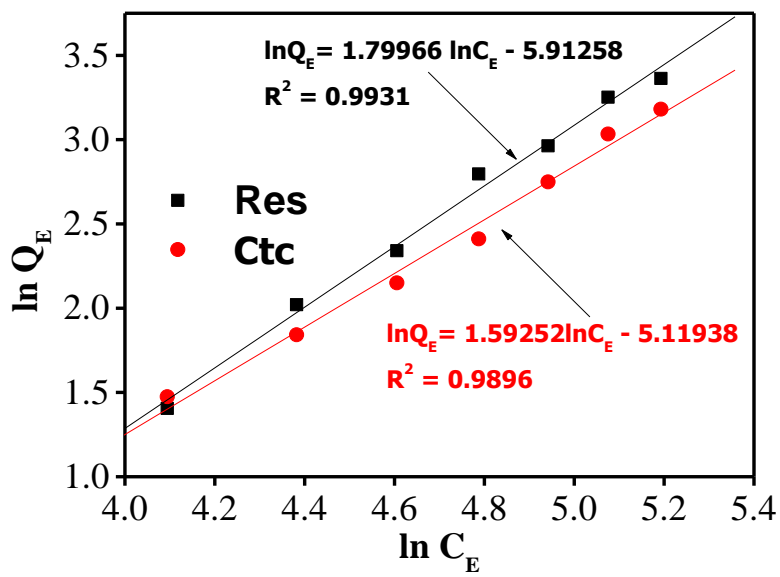

Fig. 10: Freundlich Isotherm Sorption Model. Experimental Conditions $15 \mathrm{Ml}$ of (60-180 Mg. $\left.\mathrm{L}^{-1}\right)$ Analyte, $50 \mathrm{Mg}$ of Adsorbent, Ph 2, Stirring Speed 125 Rev/Min, Contact Time 35 Min, Room Temperature.

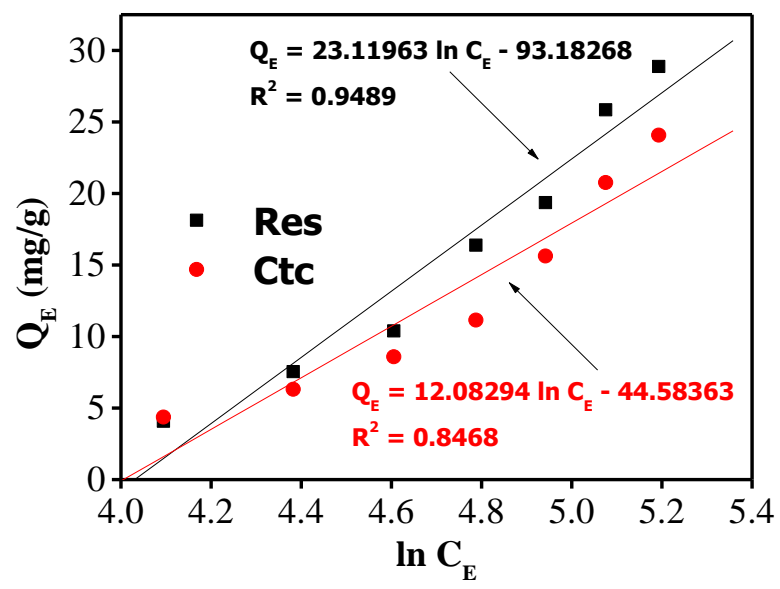

Fig. 11: Temkin Isotherm Sorption Model. Experimental Conditions: 15 Ml of (60-180 Mg.L-1 $)$ Analyte, $50 \mathrm{Mg}$ of Adsorbent, Ph 2, Stirring Speed $125 \mathrm{Rev} / \mathrm{Min}$, Contact Time 35 Min, Room Temperature.
Table 4: Langmuir, Freundlich and Temkin Constants and Adsorption Parameters

\begin{tabular}{llll}
\hline Adsorbent & & EVACSO \\
\hline Isotherm & Parameters & Res & Ctc \\
& $\mathrm{K}_{\mathrm{L}}(\mathrm{L} / \mathrm{mg})$ & 0,01097 & 0,00361 \\
Langmuir isotherm & $\mathrm{Q}_{\mathrm{m}}(\mathrm{mg} / \mathrm{g})$ & 4,473 & 16,011 \\
& $\mathrm{R}_{\mathrm{L}}$ & 0,3629 & 0,64 \\
& $\mathrm{R}^{2}$ & 0,9771 & 0,9971 \\
\multirow{5}{*}{ Freundlich isotherm } & $\mathrm{K}_{\mathrm{F}}(\mathrm{L} / \mathrm{mg})$ & 0,00271 & 0,006 \\
& $1 / \mathrm{n}$ & 1,79966 & 1,59252 \\
& $\mathrm{R}^{2}$ & 0,9931 & 0,9896 \\
Temkin isotherm & $\mathrm{K}_{\mathrm{T}}(\mathrm{L} / \mathrm{g})$ & 0,0178 & 0,250 \\
& $\Delta \mathrm{Q}(\mathrm{J} / \mathrm{mol})$ & 107,163 & 205.047 \\
& $\mathrm{R}^{2}$ & 0,9489 & 0,8468 \\
\hline
\end{tabular}

\subsubsection{Adsorption mechanism}

It appears that several barriers are erected during the development of orange: cuticle (consisting of matrix and waxes) the outermost part of the flavedo is the primary barrier; then the epidermal layer that contains the stomatal guard cells (penetration sites of chemicals and so forth), then the albedo, and finally the pulp that contains the juice. Exchanges take place by crossing all these barriers. In our case, Ctc and Res cross the barrier erected by the flavedo cuticule, weakened in very acidic medium $(\mathrm{pH}=2)$. These phenols are then adsorbed in the pores of the stomata. Their chemisorption is facilitated by the hydrogen and covalent bonds formation with the molecules of flavedo which are phenolics (e.g. flavonone glycosides, hydroxycinnamic acids), ascorbates (vitamine C), carotenoids [26-28], flavonoids Naringin and hesperidin [29] and D-limonene, a major constituent in several citrus oils (orange, lemon, mandarin, lime, and grapefruit) [30]. The adsorption of catechol and resorcinol could not be done without the contribution of these surface molecules, adsorption which is usually done in three steps: the transfer of the adsorbate to the outer surface of the adsorbent (diffusion layer), the migration of the adsorbate from the outer surface to the inner surface of the adsorbent, and the sorption of the adsorbate to the internal surface of the pores of the adsorbent. The mechanisms we propose below reflect the molecules on the surface of flavedo.

3.2.6.1. Mechanism involving limonene, main sensitizer of orange peels

The outer layer of orange peel consists of numerous oil-containing cells from which an oil of limonene, other terpenes, linalool, and a resinous residue can be expressed [31]. The terpene, limonene, is probably the principal sensitizer of orange peels. Its chemistry is vast. Its action on the acids, bases, alcohols and other reagents is described [32]. The reaction of limonene with phenols dates from 1922 [33], and the products have been patented as resins and lacquers. Products derived from this reaction could arise either by aromatic substitution (Fig. 12), formation of phenol ether [34], aromatic substitution followed by epoxidation if one refers to ocresol [35], further reaction giving polymers [36-37].

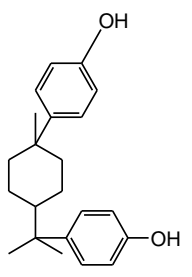

(1)

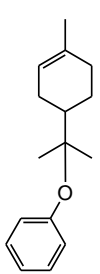

(2)

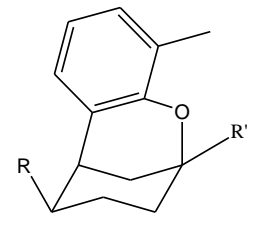

(3) $\mathrm{R}=\mathrm{Me} \mathrm{R}^{\prime}=\mathrm{iPr}$

(4) $\mathrm{R}=\mathrm{iPr} \mathrm{R}^{\prime}=\mathrm{Me}$
Fig. 12: Terpene-Phenol Monomers (Aromatic Substitution (1), Formation of Phenol Ether (2), Aromatic Substitution followed by Epoxidation (3) and (4). 
3.2.6.1.1. Probable adsorption mechanism of Ctc and Res involving limonene

Non-activated orange flavedo has the advantage of keeping all functional groups present at its surface including limonene. The action of acids on this terpene leads to a carbocation [34] which rearranges as shown in Fig. 13. With this carbocation formed, the attractive electrostatic forces between adsorbent-adsorbate are prevailing. At this stage and by similarity to the phenol [34], there would be aromatic substitution of Ctc/Res (6) and even limonenephenol ether formation (5) (Fig. 13). By analogy with o-cresol [37] the compounds (7) and (8) are possible. One can also think of the condensation of a hydroxy phenol (Ctc/Res) with 2 limonene molecules (9). It appears that limonene is involved in the chemisorption process of $\mathrm{Ctc}$ and Res by covalent bond formation (C-C and $\mathrm{C}-\mathrm{O}$ bonds).

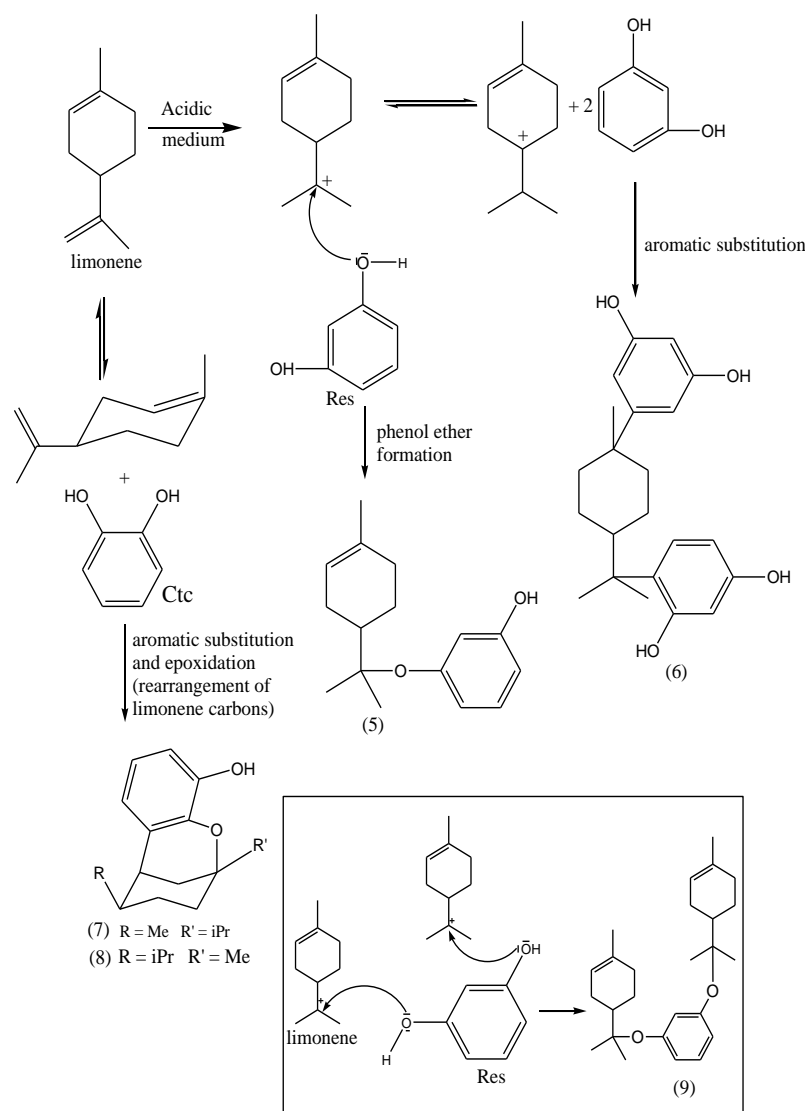

Fig. 13: Likely Reactions of Limonene on Ctc and Res.

3.2.6.2. Mechanism involving flavedo molecules having an $\mathrm{OH}$ group (vitamin $\mathrm{C}$, phenolic compounds, flavonoids, hydroxycinnamic acid): hydrogen bond formation

The common point of flavonoids, hydroxycinnamic acids and ascorbic acid (vitamin C) contained in orange flavedo is that they all have hydroxylated groups in impressive numbers (Fig. 14).
These form hydrogen bonds with the hydroxyl groups of Ctc and Res (Fig. 15).
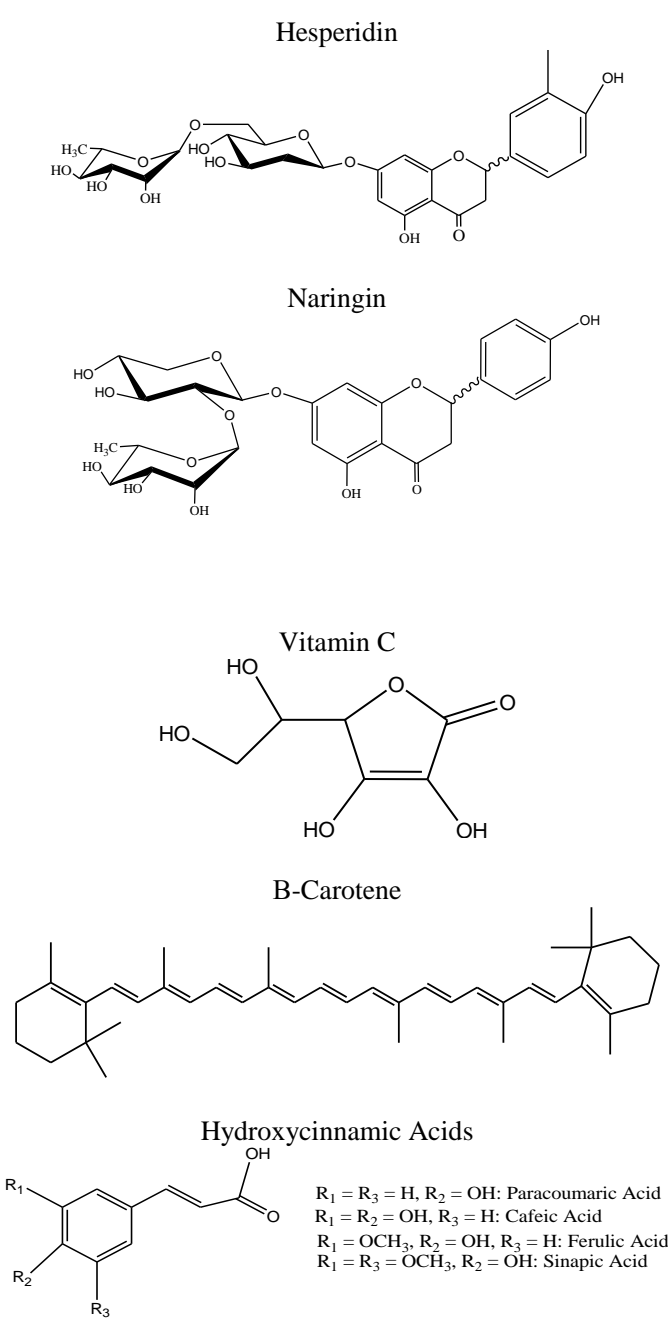

Fig. 14: Main Flavedo Components.

3.2.6.3. Mechanism involving the electron rich constituents of flavedo (carotenoids, flavonoids, hydroxycinnamic acids): II-I interactions.

Because Res and Ctc have benzene rings, it could be speculated that the main intermolecular force between these two molecules and the molecules of flavedo (flavonoids such as naringin and hesperidin, carotenoids like $\beta$-Carotene, ascorbates as vitamin $\mathrm{C}$, and hydroxycinnamic acids) should be the $\pi-\pi$ interaction (Fig. 15). The $\pi$ electrons of benzene ring of Res and Ctc interact with $\mathrm{C}=\mathrm{C}$ double bonds or the $\pi$ electrons of benzene rings of flavedo molecules by means of $\pi-\pi$ electron coupling. Jing et al. [38] thought the same thing about the adsorption of bisphenol A by graphene.

Ctc-Hesperidin interactions

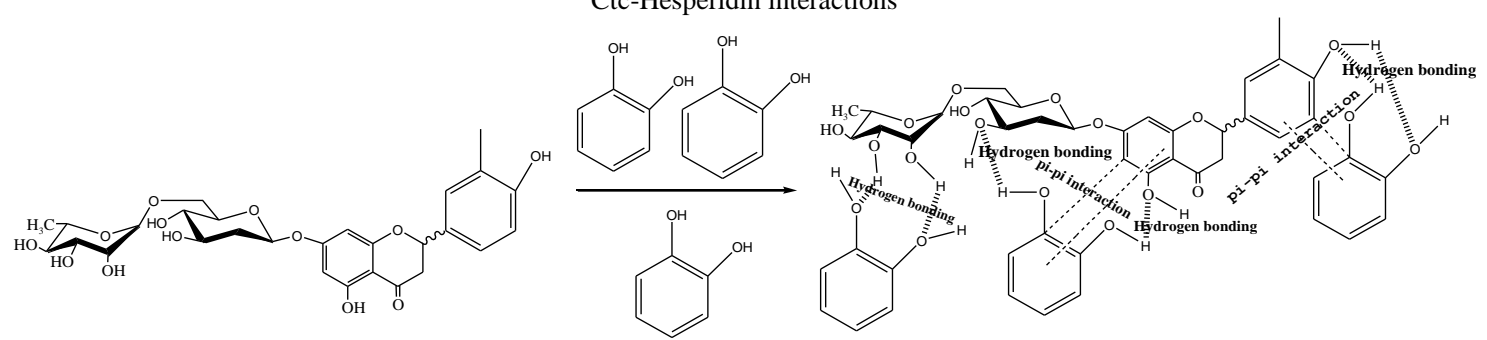




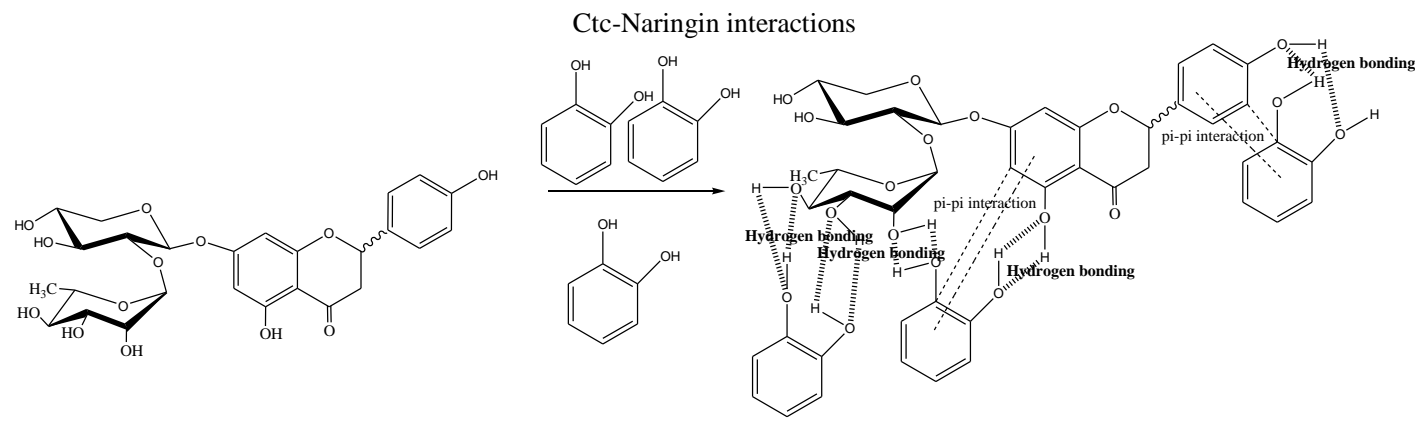

Ctc-Vitamin C interactions

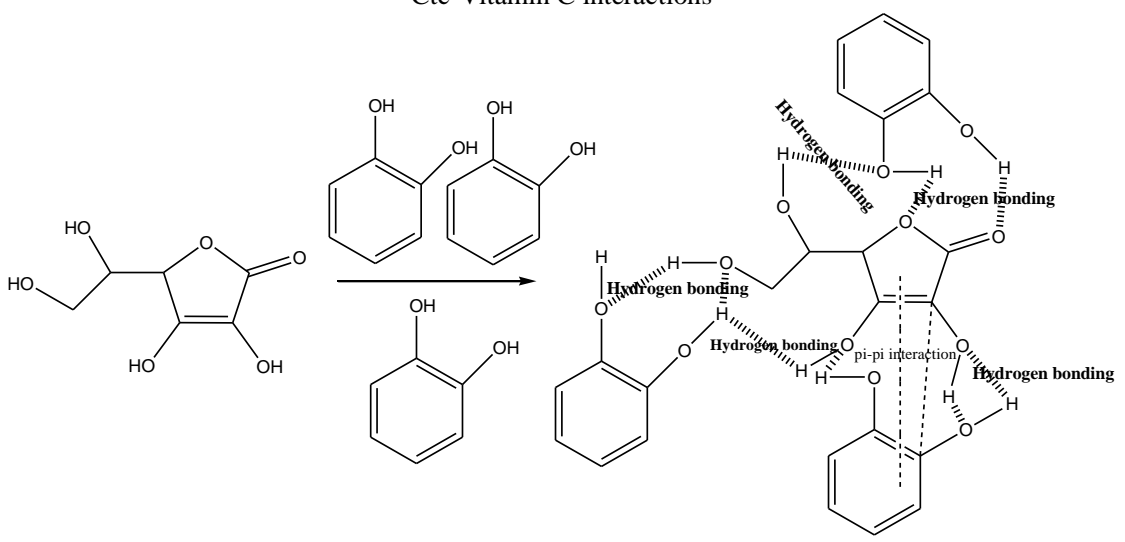

Ctc-Hydroxycinnamic acids interactions

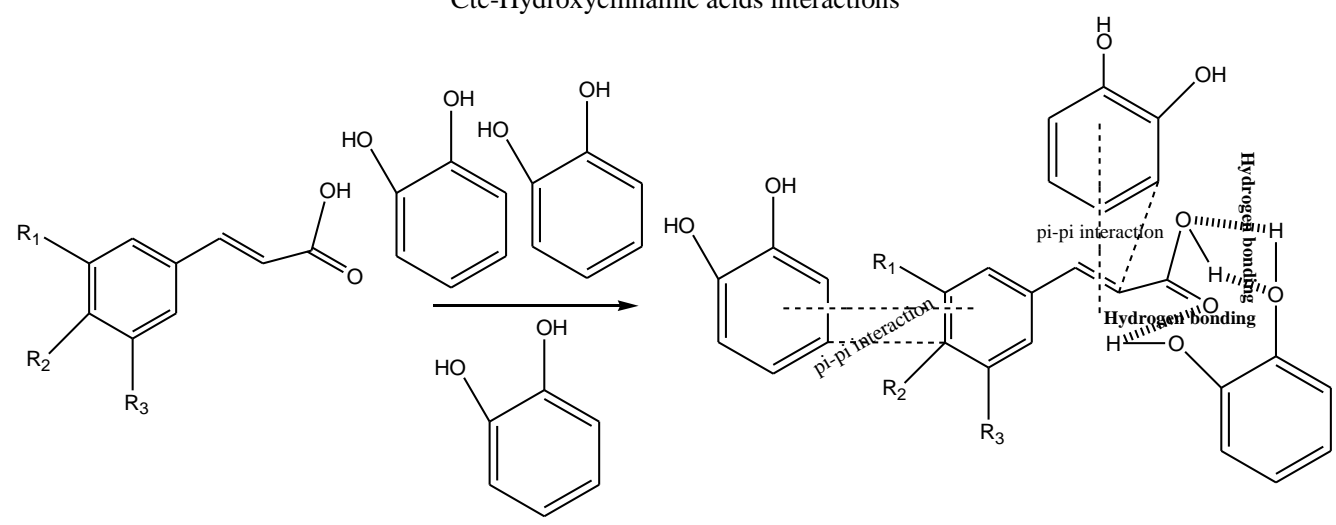

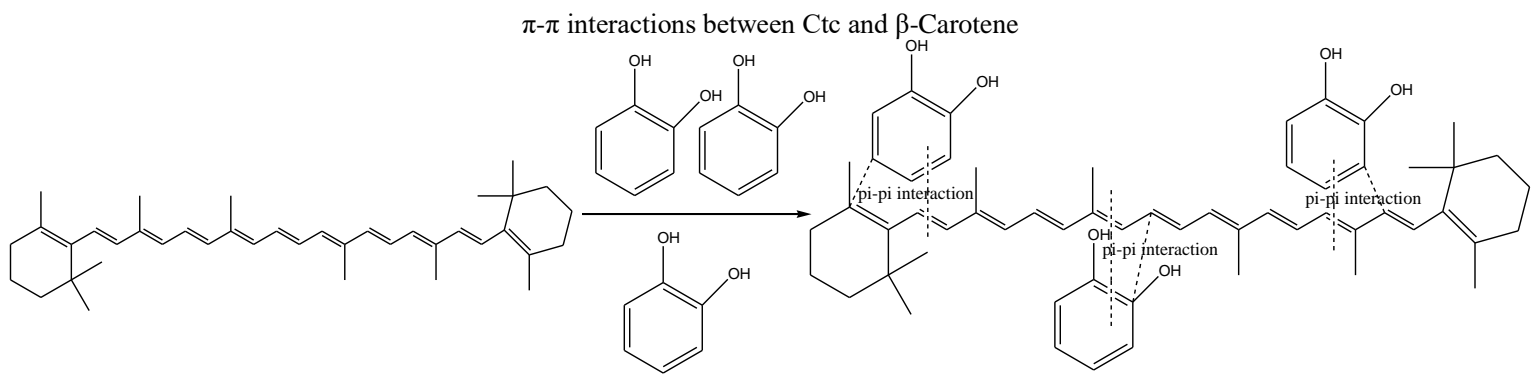

Fig. 15: Schematic of Hydrogen Bonding and $\Pi-\Pi$ Interactions between Ctc and Flavedo Components.

Thus, we can expect that tree kinds of adsorbent-adsorbate interactions might be responsible for the adsorption of Ctc and Res on orange flavedo. One of the tree interactions is the $\pi-\pi$ interaction between the benzene rings of $\mathrm{Ctc} / \mathrm{Res}$ and the flavedo molecules. The other is the attractive electrostatic interactions involving Dlimonene in acidic medium. The last but not the least is hydrogen bonding between the oxygen containing groups contained in both $\mathrm{Ctc} / \mathrm{Res}$ and flavedo.

\subsubsection{Kinetic modeling of Ctc and Res adsorption}

Four kinetic models involved in this study are summarized in Figs 16-19. Table 5 shows the values of the corresponding kinetic parameters. The pseudo-second order kinetic model perfectly de- scribes the adsorption of Ctc on EVACSO $\left(\mathrm{R}^{2}=0.9980\right.$ and $\mathrm{QE}_{\mathrm{E}}=$ $\left.27.2 \mathrm{mg} . \mathrm{g}^{-1}\right)$, very close to the experimental value $\left(25.3 \mathrm{mg} . \mathrm{g}^{-1}\right)$. It is also the case of resorcinol $\left(\mathrm{R}^{2}=0.9985\right)$ although showing a low $Q_{E}$ value (5.05 mg. $\mathrm{g}^{-1}$ ) compared to the experimental value $\left(23.8 \mathrm{mg} \cdot \mathrm{g}^{-1}\right)$. The Elovich kinetic model $\left(\mathrm{R}^{2}=0.96\right)$ provides for Res an adsorption coefficient significantly higher $(\alpha=24.743$ $\left.\mathrm{mg} \cdot \mathrm{g}^{-1} \cdot \mathrm{min}^{-1}\right)$ than the desorption coefficient $(\beta=0.02322 \mathrm{mg} \cdot \mathrm{g}$ $\left.{ }^{1} \cdot \mathrm{min}^{-1}\right)$, indicating an attractive interaction between adsorbent and adsorbate.

It should be noted that the factor which limits the adsorption of Res is essentially the intraparticle diffusion, which is not the case of Ctc (Fig. 19). All the above considerations are in favor of a chemisorption of Res and Ctc in the inner surface of orange flavedo [13]. 


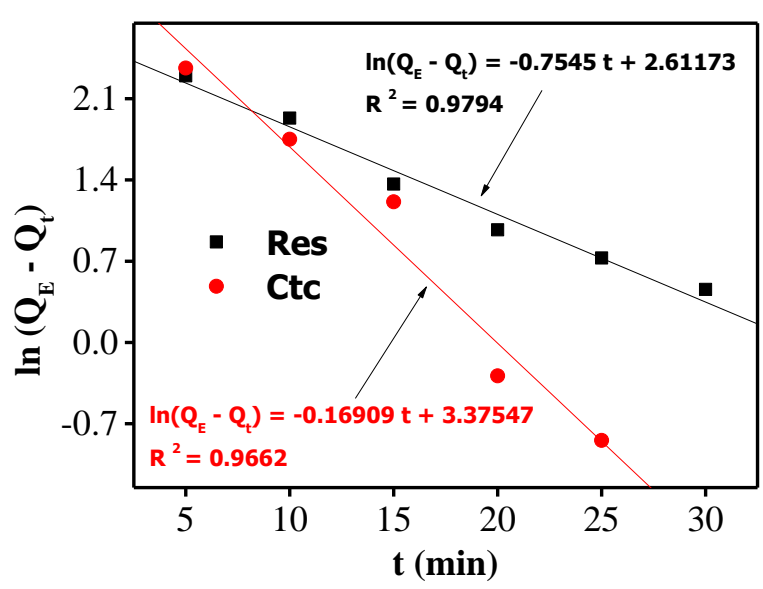

Fig. 16: Linearized Pseudo-First Order Plots.

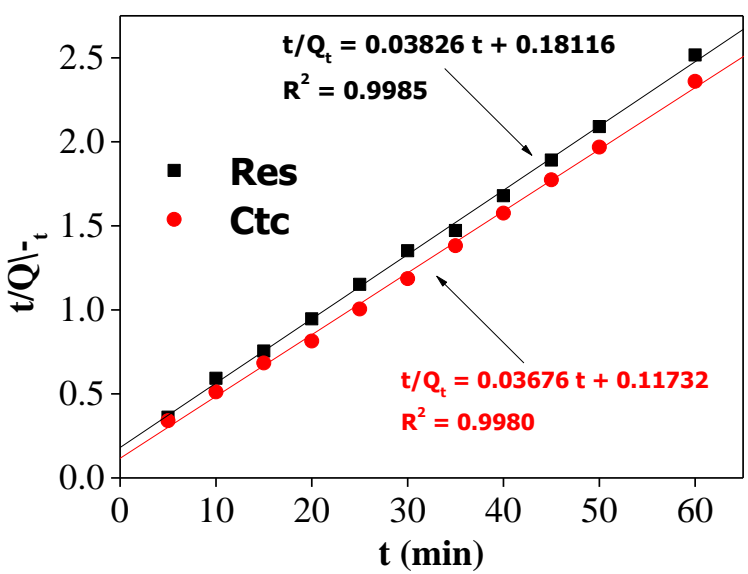

Fig. 17: Linearized Pseudo-Second Order Plots.

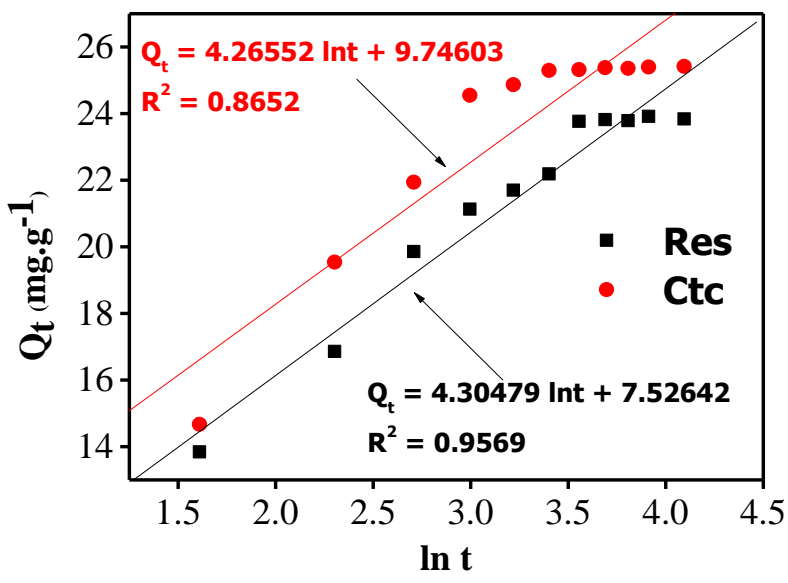

Fig. 18: Linearized Elovich Model Plots.

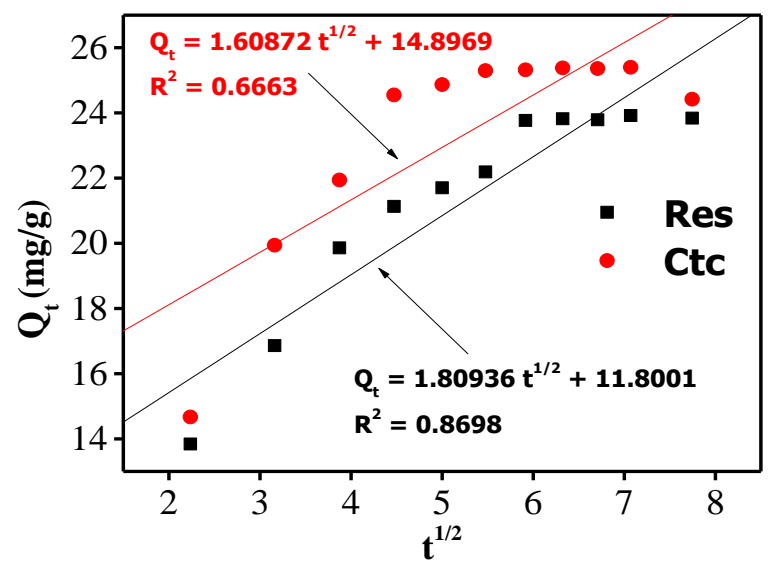

Fig. 19: Linearized Intraparticle Diffusion Model Plots.
Table 5: Kinetic Constants and Parameters of Four Adsorption Kinetic Models Involved in the Sorption of Ctc and Res Using EVACSO

\begin{tabular}{llll}
\hline Adsorbent & & EVACSO \\
\hline Kinetic models & Parameters & Res & Ctc \\
& $\mathrm{K}_{1}\left(\mathrm{~min}^{-1}\right)$ & 0.7541 & 0.16909 \\
Pseudo-first order model & $\mathrm{Q}_{\mathrm{E}}\left(\mathrm{mg} \cdot \mathrm{g}^{-1}\right)$ & 13.62 & 29.24 \\
& $\mathrm{R}^{2}$ & 0.9794 & 0.9662 \\
& $\mathrm{~K}_{2}\left(\mathrm{~g} \cdot \mathrm{min}^{-1} \cdot \mathrm{mg}^{-1}\right)$ & 1.0165 & 0.0115 \\
& $\mathrm{Q}_{\mathrm{E}}\left(\mathrm{mg} \cdot \mathrm{g}^{-1}\right)$ & 5.038 & 27.20 \\
Pseudo-second order model & $\mathrm{R}^{2}$ & 0.9985 & 0.9980 \\
& $\mathrm{~h}\left(\mathrm{mg} \cdot \mathrm{min}^{-1} \cdot \mathrm{g}^{-1}\right)$ & 25.80 & 8.524 \\
& $\alpha\left(\mathrm{mg} \cdot \mathrm{g}^{-1} \cdot \mathrm{min}^{-1}\right)$ & 24.743 & 41.905 \\
Elovich kinetic model & $\beta\left(\mathrm{g} \cdot \mathrm{mg}^{-1}\right)$ & 0.02322 & 0.2344 \\
& $\mathrm{R}^{2}$ & 0.9569 & 0.8652 \\
& $\mathrm{~K}_{\mathrm{d}}\left(\mathrm{mg} \cdot \mathrm{g}^{-1} \cdot \mathrm{min}^{-1 / 2}\right)$ & 1.8009 & 1.60872 \\
Intraparticle diffusion model & $\mathrm{C}_{1}(\mathrm{mg})$ & 11.8001 & 14.8969 \\
& $\mathrm{R}^{2}$ & 0.8698 & 0.6663 \\
\hline
\end{tabular}

\section{Conclusion}

Orange peels, a major source of nutrient-rich residues also have important surface properties. In this study it is shown that they can be applied to the removal of catechol and resorcinol in solution. Surface molecules responsible for the adsorption of the two phenols are mainly limonene, carotenoids, flavonoids and hydroxycinnamic acids. They are responsible for the sorption of catechol and resorcinol by formation of hydrogen bonds and $\pi-\pi$ interactions, and by covalent bond formation with the limonene. The adsorption is multilayer and the surface of flavedo heterogeneous. The kinetics are second order. The intraparticle diffusion is the limiting factor for the adsorption of resorcinol, which is not the case for catechol where other factors, in addition to the internal diffusion are to be considered. These results revealed that orange flavedo could be used as alternative low cost biosorbent for catechol and resorcinol removal from aqueous solution.

\section{Acknowledgements}

We thank the Ministry of Higher Education of Cameroon for the special premium paid quarterly to Lecturers, and MIPROMALOCameroon for his contribution to the analysis of materials.

\section{References}

[1] Hakim, I.A., Harris, R.B. (2001). Joint effects of citrus peel use and black tea intake on the risk of squamous cell carcinoma of the skin Dermatology, 1:3. https://doi.org/10.1186/1471-5945-1-3.

[2] Albrigo, G. (1986). Peel morphology and fruit blemishes. Citrus Flowering, fruit set and development. Gainesville, University of Florida, 73-80.

[3] Petracek, P.D. (1997). Peel morphology and fruit blemishes. Citrus Flowering and Fruiting Short Course, CREC, Lake Alfred, 18-118.

[4] Agusti, M.; Zaragoza, S.; Bleiholder, H.; Buhr, L.; Hack, H.; Klose, R.; Stauss, R. (1997). Adaptation of the BBCH scale for the description of citrus fruits phenological stages, Fruits, 52, 287-295.

[5] Phutdhawong, W.; Chowwanapoonpohn, S.; Buddhasukh, D. (2000). Electrocoagulation and subsequent recovery of phenolic compounds, Analytical Sciences, 16, 1083-1084. https://doi.org/10.2116/analsci.16.1083.

[6] Schweigert, N.; Zehnder, A.J.B.; Eggen, R.I.L. (2001). Chemical properties of catechols and their molecular modes of toxic action in cells, from microorganisms to mammals, Environmental Microbiology, 3, 81-91. https://doi.org/10.1046/j.1462-2920.2001.00176.x.

[7] Raff, R.; Ettling, B.V. (1966). Hydroquinone, resorcinol and pyrocatechol, in: Kirk RE, Othmer D.F. (Eds.), Encyclopedia of Chemical Technology, Wiley, New York, 462-492.

[8] Steiman, R.R; Seigle-Murandi, F.; Chritov, L.P. (1999). Growth of 1044 strains and species of fungi on 7 phenolic lignin model compounds, Chemosphere, 38, 2549-2559. https://doi.org/10.1016/S0045-6535(98)00462-7.

[9] Van Duursen, M.B.M.; Sanderson, J.T.; De Jong, P.C.; Kraaij, M.; Van den Berg, M. (2004). Phytochemicals inhibit catechol-omethyl transferase activity in cytosolic fractions from healthy human mammary tissues: implications for catechol estrogen-induced 
DNA damage, Toxicological Sciences, 81, 316-324. https://doi.org/10.1093/toxsci/kfh216.

[10] Prager, J.C. (1996). Environmental Contaminant Reference Data book Volume 2, Van Nostrand Reinhold, New York, p. 560.

[11] Lopez-Ramon, M.V.; Stoeckli, F.; Moreno-Castilla, C.; CarrascoMarin, F. (1999). On the characterization of acidic and basic surface sites on carbons by various techniques. Carbon, 37, 12151221. https://doi.org/10.1016/S0008-6223(98)00317-0.

[12] Lagergren, S. (1898). Zur theorie der sogenannten adsorption geloster stoffe, Kungliga Svenska Veten skapsakademiens, Handlingar, 24 (4), 1-39.

[13] Ho, Y.S. (2006). Review of second-order models for adsorption systems, Journal of Hazardous Materials, B136, 681-689. https://doi.org/10.1016/j.jhazmat.2005.12.043.

[14] Langmuir, I. (1918). The adsorption of gases on plane surfaces of glass, mica, and platinum. Journal of the American Chemical Society, 40, 1361-1403. https://doi.org/10.1021/ja02242a004.

[15] Freundlich, H. (1906). Over the adsorption in the solution. Journal of Physical Chemistry, 57, 385-470.

[16] Bourdais, E.; Fytianosand, F.; Bozani, E. (2002). Sorption Description isotherms of Dyes from aqueous solutions and Waste Waters with Different Sorbent materials, Global Nest: the Int. J., 4, 75-83.

[17] Tempkin, M.I.; Pyzhev, V. (1940). Kinetics of ammonia synthesis on promoted iron catalyst. Acta Physicochimica USSR, 12, 327356.

[18] Yanbo, Z.; Ping, L.; Jun, L. (2012). Application of natural biosorbent and modified peat for Bisphenol A removal from aqueous solutions, Carbohydrate Polymers, 88, 502-508. https://doi.org/10.1016/j.carbpol.2011.12.034.

[19] Arami, M.; Limaee, N.Y.; Mahmoodi, N.M.; Tabrizi, N.S. (2005) Removal of dyes from colored textile wastewater by orange peel adsorbent: Equilibrium and kinetic studies, Journal of Colloid and Interface Science, $288, \quad 371-376$. https://doi.org/10.1016/j.jcis.2005.03.020.

[20] Mafra, M.R.; Igarashi-Mafra, L.; Zuim, D.R.; Vasques, É.C.; Ferreira, M.A. (2013). Adsorption of remazol brilliant blue on an orange peel adsorbent. Brazilian Journal of Chemical Engineering, 30, 657-665. https://doi.org/10.1590/S0104-66322013000300022.

[21] Guan, Q.; Xiong, W.; Zhou, L.; Liu, S. (2016). Facile synthesis of nitrogen-doped porous carbon-gold hybrid nanocomposite for mercury (II) ion electrochemical determination, Electroanalysis, 28 , 133-139. https://doi.org/10.1002/elan.201500481.

[22] Kumar, A.; Kumar, S.; Kumar, S. (2003). Adsorption of resorcino and catechol on activated carbon: equilibrium and kinetics. Carbon, 41, 3015-3025 https://doi.org/10.1016/S0008-6223(03)00431-7.

[23] Mohamed, F.S.; Khater, W.A.; Mostafa, M.R. (2006). Characterization and phenols sorptive properties of carbons activated by sulphuric acid, Chemical Engineering Journal, 116, 47-52.

[24] Moreno-Castilla, C. (2004). Adsorption of organic molecules from aqueous solutions on carbon materials, Carbon, 42, 83-94. https://doi.org/10.1016/j.carbon.2003.09.022.

[25] Fabian, A.U.; Aloysius, A.P.; Abiola, V.I. (2014). Thermodynamic Properties of Chromium (III) Ion Adsorption by Sweet Orange (Citrus sinensis) Peels, American Journal of Analytical Chemistry, 5, 666-673. https://doi.org/10.4236/ajac.2014.510074.

[26] Marchand, L. (2002). Cancer preventive effects of flavonoids-A review, Biomedicine \& Pharmacotherapy, 56, 296-301. https://doi.org/10.1016/S0753-3322(02)00186-5.

[27] Halliwell, B. (1996). Antioxidants in human health and disease, Annual Review of Nutrition, 16, 33-50. https://doi.org/10.1146/annurev.nu.16.070196.000341.

[28] Rao, A.V.; Rao, L.G. (2007). Carotenoids and human health, Pharmacological Research, 55, 207-216. https://doi.org/10.1016/j.phrs.2007.01.012.

[29] Escobedo-Avellaneda, Z.; Gutierrez-Uribe, J.; Valdez-Fragoso, A.; Torres, J.A.; Welti-Chanes, J. (2014). Phytochemicals and antioxidant activity of juice, flavedo, albedo and comminuted orange, Journal of Functional Foods, 6, 470-481. https://doi.org/10.1016/j.jff.2013.11.013.

[30] Sun, J. (2007). D-Limonene: Safety and Clinical Applications, Alternative Medicine Review, 12, 259-264.

[31] Mondello, L.; Casilli, A.; Tranchida, P.Q. ; Dugo, P.; Dugo, G. (2005). Comprehensive two-dimensional GC for the analysis of Citrus essential oils, Flavour and Fragrance Journal, 20, 136-140. https://doi.org/10.1002/ffj.1506.

[32] Thomas, A.F.; Bessiere, Y. (1998). Limonene, Natural Product Re ports, 291-309.

[33] Wuyts, H. Br. P. 204754, June 29, 1922 Cheni. Zenrralbl., 1923, IV, 951.
[34] Hultzsch, K. (1938). Angew. Cliem, 51, 920. https://doi.org/10.1002/ange.19380515203.

[35] Kuzakov, E.V.; Schmidt, E.N. (2000). Synthesis of terpenophenols via direct alkylation of phenols by terpenes, Chemistry of Natural compounds, 36, 245-257. https://doi.org/10.1007/BF02238328.

[36] Remmelsburg, A.L.V. (1949). Hercules Powder Co., U.S. P. 2471455, May 31, Chem. Ahstr., 43, 6237.

[37] Fink, J.K. (2013). Reactive polymers fundamentals and applications. A concise Guide to industrial polymers, $2^{\text {nd }}$ edition, Elsevier, $524 \mathrm{pp}$.

[38] Jing, X.; Li, W.; Zhu, Y. (2012). Decontamination of bisphenol A from aqueous solution by graphene adsorption, Langmuir, 28, 8418-8425. https://doi.org/10.1021/la301476p 